\title{
Ectopic pregnancy at the Gambian Tertiary hospital
}

\author{
Matthew Anyanwu' ${ }^{1,2,3}$, Grace Titilope ${ }^{2}$
}

1. Edward Francis Small Teaching Hospital (EFSTH), Banjul The Gambia.

2. School of Medical and Allied Health Sciences, university of The Gambia.

3. College of Medicine American International University West Africa.

\begin{abstract}
Background/Aims: Ectopic pregnancy is a gynaecological emergency with significant burden of maternal mortality and morbidity in the tropics. The incidence reported in the literature range

from 1:60 to 1:250 pregnancies. The aim was to determine incidence and risk factors of ectopic pregnancy in the Gambia.
\end{abstract}

Methodology: A longitudinal study of ectopic pregnancy at Gambian tertiary hospital from

January 2016 to April 2018. Data was collected from patients' folders, entered into SPSS version 20 and analysed with descriptive statistics. The test of variation and significance was by ANOVA and Chi-square respectively with error margin set at 0.05 and confidence interval of $95 \%$.

Results: A total number of 2562 pregnancies were recorded, 43 were ectopic pregnancies. The estimated incidence was $0.2 \%$. Majority of the patients were between $26-35$ years $(56 \%)$,

primiparous $(32 \%)$, heterogeneous marriage $(82 \%)$ and housewives $(86 \%)$. Occupation was not associated with ruptured or unruptured ectopic pregnancy (p-0.421). Low parity was associated with more ectopic pregnancy than high parity ( $\mathrm{p}-0.001)$. The commonest clinical feature was abdominal pain (65.1\%), whilst the most prominent risk factors were pelvic inflammatory disease $(27.9 \%)$ and previous abortion (23.3\%). Ectopic pregnancy was seasonal.

Conclusion: The incidence rate of $0.2 \%$ was in the range reported in the literature. Low parity, previous abortion and pelvic inflammatory disease were the risk factors.

Keywords: Ectopic; pregnancy; incidence; risk factors.

DOI: https://dx.doi.org/10.4314/ahs.v21i1.38

Cite as: Anyanmu M, Titilope G. Ectopic pregnancy at the Gambian Tertiary hospital. Afri Health Sci. 2021;21(1):295-303. bttps:/ / dx.doi.org/10.4314/ahs.v21i1.38

\section{Introduction}

Ectopic pregnancy (EP) is the abnormal implantation of a conceptus outside the normal endometrial lining of the uterus ${ }^{1}$. It could also be defined as a pregnancy in which implantation occurs in a site other than the uterine endometrial lining. It is a very important gynaecological emergency and a major contributing factor to the burden of maternal mortality and morbidity in the early half of pregnancy ${ }^{2}$.

The incidence of ectopic pregnancy is increasing worldwide and varied from 1 in 60 to 1 in 250 pregnancies $^{1}$.

\section{Corresponding author:}

Matthew Anyanwu,

University of the Gambia School of Medicine

and Allied Sciences Department of Obstetrics

and Gynaecology Banjul the Gambia;

P.O.Box1646 UTG Banjul.

(220)-9922933 or (220)-7786700

Email: anyanwum@yahoo.com
This wide variation has been attributed to degree of genital tract pathologies and contraceptive practice of the population ${ }^{3}$. In sub-Saharan Africa the incidence of ectopic pregnancy is much more difficult to determine especially where maternal deaths that occur due to ectopic pregnancy are not frequently reported or documented $^{4}$.

It is a known fact that ectopic pregnancy (EP) contributes immensely to maternal mortality especially in the tropics. Therefore, efforts to reduce cases of ectopic pregnancy; ensure early diagnosis and appropriate management is crucial in reducing maternal mortality due to ectopic pregnancy. The sustainable development goal 3 states that global maternal mortality ratio should be less than 70 per 100000 births, with no country having a maternal mortality rate of more than twice the global average $^{5}$. Therefore, reducing deaths from EP is one essential element towards realization of this goal.

The occurrence of ectopic pregnancy has in part been linked to the presence of risk factors 
although some may occur without any risk factor documented. Overall, the risk factors implicated were previous ectopic pregnancy, pelvic inflammatory disease, multiple sexual partners, previous tubal surgeries, intrauterine contraceptive device, smoking, in vitro fertilization, infertility, vaginal douching, migration of the ovum to the contralateral tube, sexually transmitted disease, maternal age, kinking or scarring of the fallopian tube, prior induced abortion, delayed ovulation, and abdominal surgery ${ }^{6-9}$. Some other scholars working elsewhere have included consanguinity as a risk factor in women less than 20 years of age $\mathrm{e}^{10,11}$. Congenital malformation of the fallopian tubes due to exposure to diethylstilbestrol is also a risk factor ${ }^{12}$.

The difficulty in reaching a diagnosis has been a contributing factor in the adverse outcome of ectopic pregnancy. The late arrival to hospital and delay in reaching a diagnosis due to multiple factors in the tropics continue to dominate the terrain. In reaching a diagnosis; clinical history, serum human chorionic gonadotrophin (hCG) and a transvaginal scan in combination as a triad is essential. Effective application of the triad certainly may reduce the dilemma. However, laparoscopy can be used for both diagnosis and treatment but is no longer the gold standard of reaching a diagnosis ${ }^{13}$.

Late diagnosis is a risk factor of ruptured ectopic which may be associated with torrential loss of blood. Therefore, haemorrhage is the major reason why it is a leading cause of mortality in women with or without vaginal bleeding which may be subtle or massive. At times vaginal bleeding may not be seen as patient may present in shock and death may result within a very short span of time.

In the Gambia, ectopic pregnancy is still a cause of death as haemorrhage remains the leading cause of maternal mortality ${ }^{14}$. Therefore, the knowledge on the risk factors and incidence of ectopic pregnancy in the Gambia may inform practice and develop a baseline for estimation of trend and its role in the rate of maternal mortality.

\section{The methodology}

A retrospective longitudinal study of ectopic pregnancy from January 2016 to April 2018 was conducted at Edward Francis Small Teaching Hospital, the only teaching hospital and tertiary referral hospital in the country. It is located in Banjul.

Study population: All patients with early pregnancy issues seen at the gynaecology clinic or ward were identified but only those with ectopic pregnancy as a diagnosis was considered for analysis during the period under review. Women beyond the child bearing age and those without pregnancy related issues were excluded from the study.

Procedure: A longitudinal descriptive study of ectopic pregnancy at the gynaecology inpatient and outpatient department of Edward Francis Small Teaching Hospital (EFSTH). Data was collected from patients' folders after going through the ledger books recording total number of patients in the period under review and their hospital numbers through which the folders were traced. The denominator of the incidence estimation was the number of women in the reproductive age that had confirmed pregnancy during the period under review.

A data collection tool was developed with variables designed to assess the objectives of the study. The variables include; socio-demographic characteristics of the study population, suggested risk factors from the literature review, use of contraceptive and clinical features. Consistent check was used to ensure accurate data entering into SPSS version 20 software. The results were expressed in descriptive statistics by simple percentage. The test of variation and significance was by ANOVA and Chi-square respectively with error margin set at 0.05 and confidence interval of $95 \%$.

\section{Results}

During the period under view (January 2015 to April 2018) a total number of 2562 pregnancy was recorded out of which 43 were ectopic pregnancies. The estimated incidence rate was $0.2 \%$. 
Table 1: shows socio-demographic characteristics of the study population

\begin{tabular}{|c|c|c|}
\hline \multirow[t]{2}{*}{ Age } & \multicolumn{2}{|l|}{ 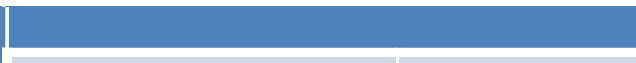 } \\
\hline & Frequency & Percentage (\%) \\
\hline $15-20$ & 4 & 9.0 \\
\hline $21-25$ & 9 & 20.9 \\
\hline $26-30$ & 12 & 27.9 \\
\hline $31-35$ & 12 & 27.9 \\
\hline $36-40$ & 6 & 14.0 \\
\hline \multicolumn{3}{|l|}{ Marital status } \\
\hline Single & 4 & 9.3 \\
\hline Married & 35 & 81.4 \\
\hline Divorced & 2 & 4.7 \\
\hline Widowed & 2 & 4.7 \\
\hline \multicolumn{3}{|l|}{ Ethnicity } \\
\hline Wollof & 8 & 18.6 \\
\hline Mandika & 11 & 25.6 \\
\hline Fula & 4 & 9.3 \\
\hline Jola & 12 & 27.9 \\
\hline Others & 8 & 18.6 \\
\hline \multicolumn{3}{|l|}{ Occupation } \\
\hline House Wives & 37 & 86.0 \\
\hline Government Workers & 6 & 14.0 \\
\hline \multicolumn{3}{|l|}{ Residential Location } \\
\hline Urban & 28 & 65.1 \\
\hline Rural & 15 & 34.9 \\
\hline \multicolumn{3}{|l|}{ Parity Level } \\
\hline $\mathbf{0}$ & 6 & 14.0 \\
\hline 1 & 14 & 32.6 \\
\hline 2 & 8 & 18.6 \\
\hline 3 & 2 & 4.7 \\
\hline 4 & 6 & 14.0 \\
\hline 5 and Above & 7 & 16.3 \\
\hline Total & 43 & 100 \\
\hline
\end{tabular}

The analysis revealed that most of the study population was aged between 26-35 (56\%) years which can be categorized as young adults in the study area. The result of the test of significant revealed ( $\mathrm{F}=8.940$, $\mathrm{p}=0.000<0.05)$ which inferred a significant difference in the age of the study population. Majority were in heterogeneous marriage $(82 \%)$. The distribution of ethnicity showed Jola (27.9\%) and Mandinka (25.6\%) being the most affected tribes.

Regarding occupation, the majority $(86.0 \%)$ were housewives. 
Table 2 shows risk factors

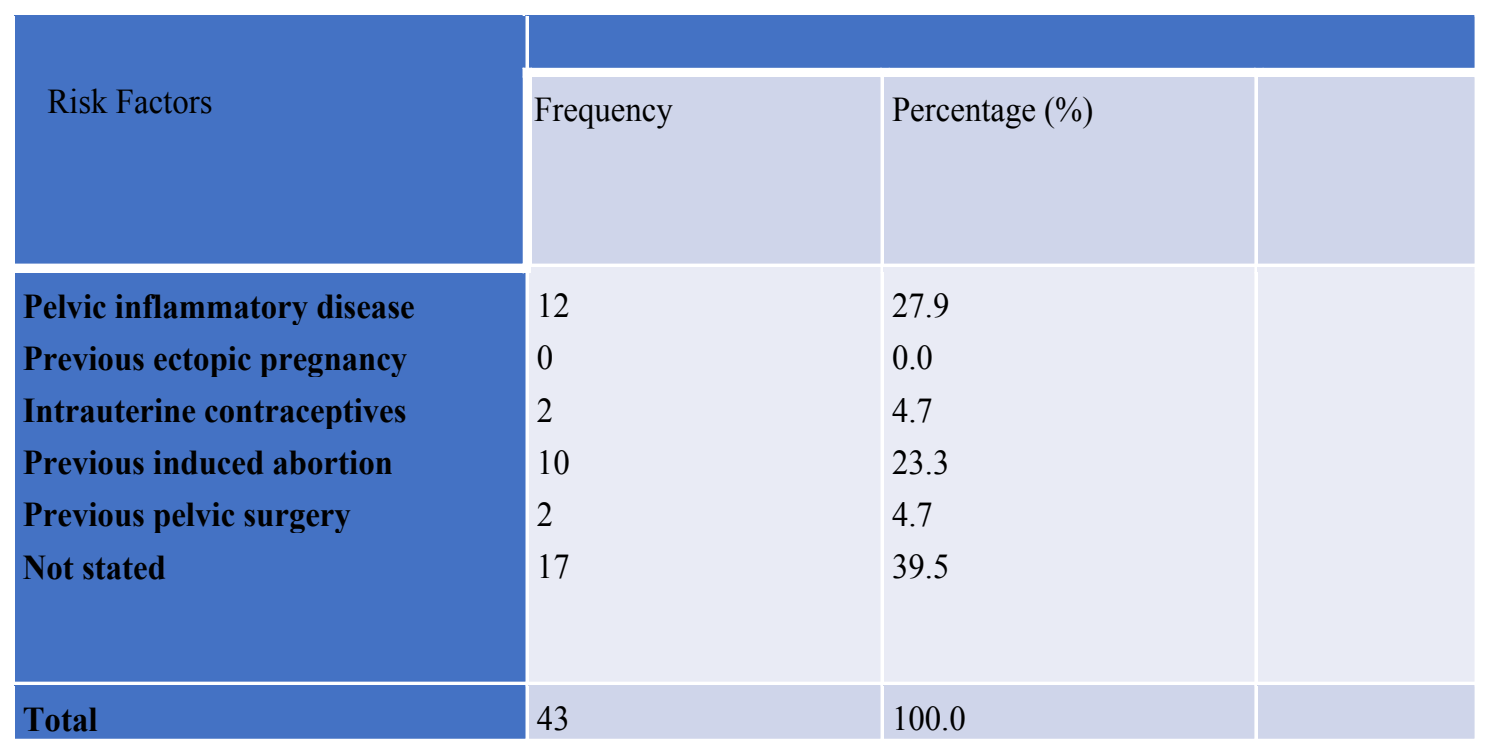

Pelvic inflammatory disease $(27.8 \%)$ and previous in- factors. In 17 patients $(39.5 \%)$ no risk factor was stated duced abortion $(23.3 \%)$ were the most common risk in the folder.

Table 3: shows the relationship of occupation with REP and UEP

\begin{tabular}{|l|l|l|l|} 
& Housewives & Government workers & p-value \\
\hline Unruptured & 7 & 2 & 0.421 \\
\hline Ruptured & 30 & 4 & \\
\hline Total & 37 & 6 & \\
\hline
\end{tabular}

The Chi-Square analysis $\left(\boldsymbol{x}^{2}=0.48, \mathrm{p}=0.421>0.05\right)$ in- and ruptured or unruptured ectopic pregnancy. Rupdicates no significant association between occupation tured EP accounted for $34(79.01 \%)$ and unruptured EP accounted for $9(20.09 \%)$.

Table 4: shows the relationship of parity and age to frequency of EP

\begin{tabular}{|c|c|c|c|}
\hline Age & Ectopic pregnancy & p-value & \\
\hline $21-25$ & 9 & 0.000 & 23.203 \\
\hline $26-30$ & 12 & & \\
\hline$>35$ & 6 & & \\
\hline Total & 27 & & \\
\hline \multicolumn{4}{|l|}{ Parity } \\
\hline$<4$ & 30 & 0.001 & \\
\hline$>4$ & 13 & & \\
\hline Total & 43 & & \\
\hline
\end{tabular}

ANOVA analysis $(\mathrm{F}=172.4$, p-value $<0.001<0.05)$. ference or variation in the age and frequency of ecThere was significant association of low parity and topic pregnancy. The age group of 26-35 was signifiectopic pregnancy. Similarly, there was significant dif- cantly associated with ectopic pregnancy (f $=23.203$, $\mathrm{p}=0.000<0.05)$. 


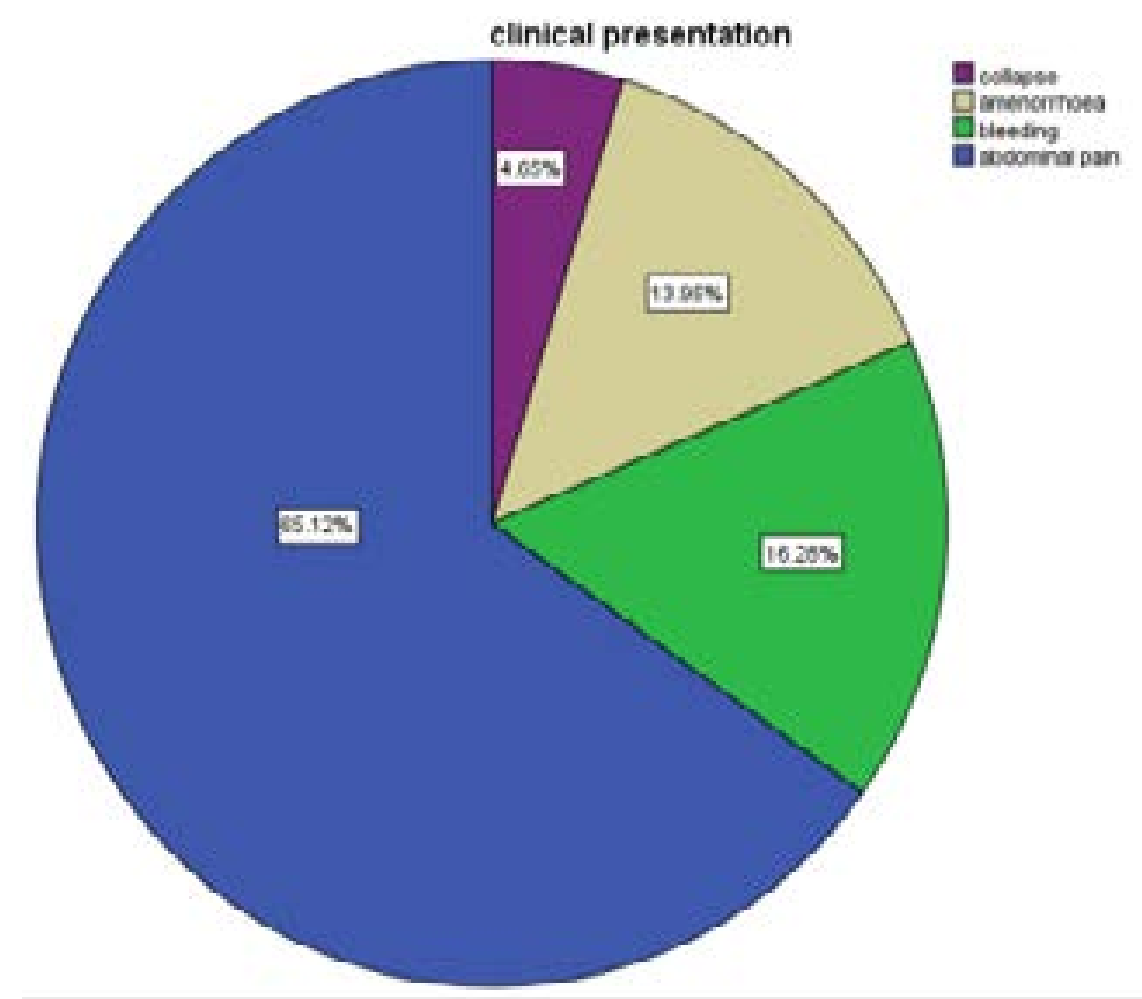

Figure 1: Clinical presentation of the patients as stated in the folders

Distribution of clinical presentation of the patients pain as the primary complaints. This may or may not be showed that majority (65\%) presented with abdominal associated with bleeding (16.3\%), amenorrhea (14\%) or collapse (5\%).

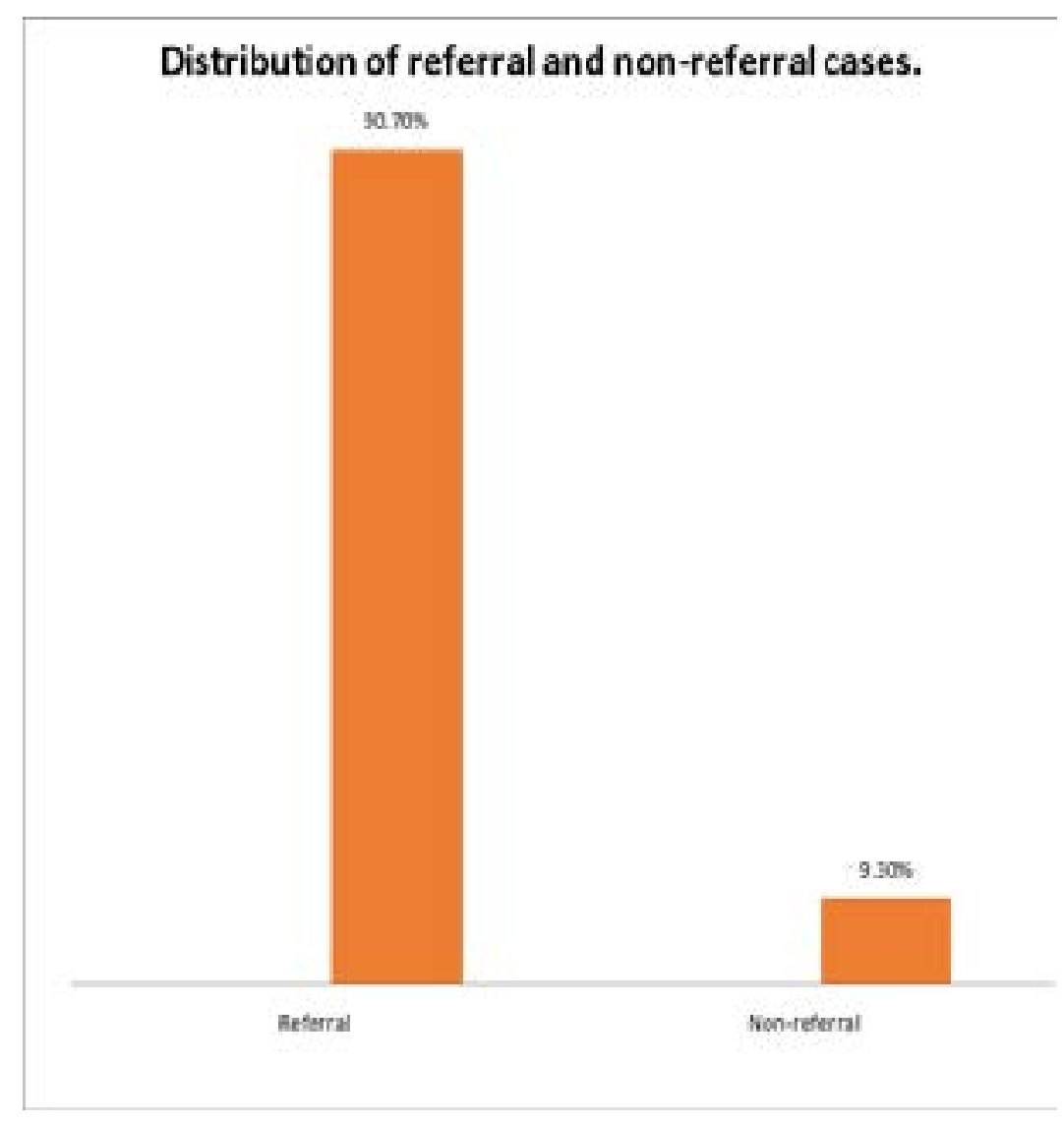

Fig 2: shows distribution of referred and non-referred cases 
This showed that most of the patients were referred (90.7\%).

The trend of ectopic pregnancy for a 2 -year period from 2016, 2017 and part of 2018; showed sharp increase consistently between February and March. A second increase was from July to October before a sharp fall in December for all the years. The double peak trend observed was in cold and rainy seasons of the Gambia.

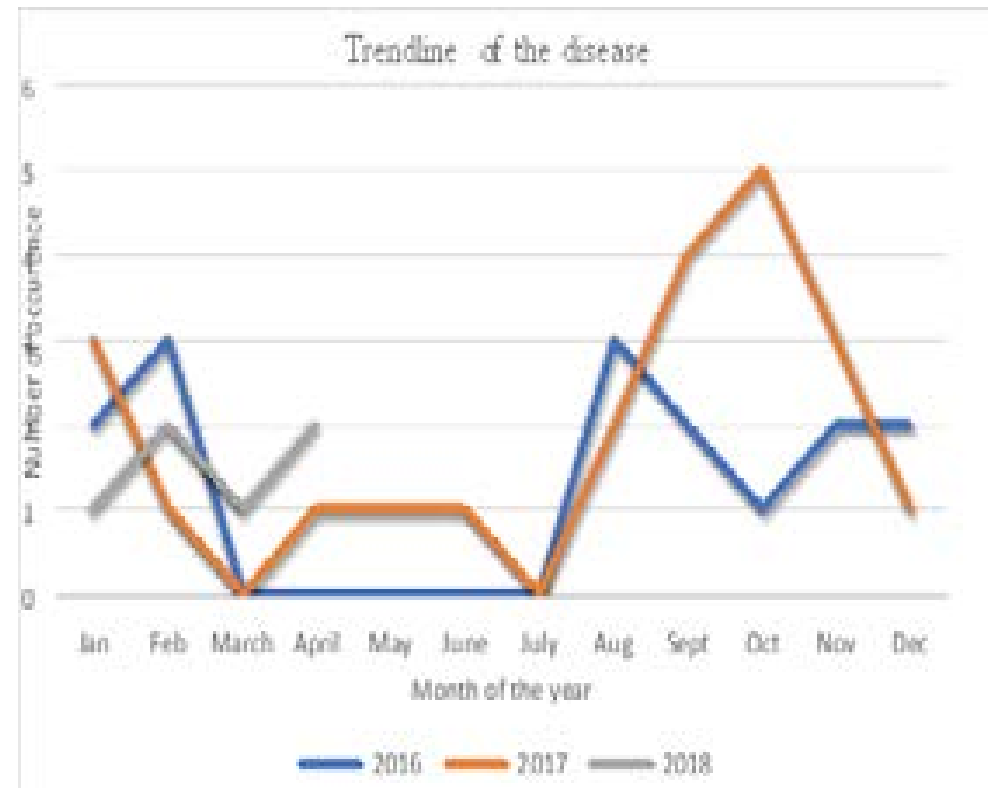

Fig 3: Trend of disease from year 2016 - 2018

\section{Discussion}

The incidence of ectopic pregnancy in this study was $0.2 \%$ of all pregnancy during the period under review. This incidence was lower than figures reported in North-East Nigeria (0.6\%), India (0.6\%), Ghana $(2.5 \%)$, Saudi Arabia $(0.58 \%)$ and Southern Nigeria $(3.3 \%)^{11,5,3,15,16}$. The incidence of ectopic pregnancy showed a world-wide variation as the Western worldthe United Kingdom $(0.01 \%)$ and the United States of America $(0.02 \%)^{17,18}$ had very low incidence of ectopic pregnancy which was comparable with $0.02 \%$ incidence recorded in the North-West (Sokoto) part of Nigeria ${ }^{19}$. This discovery made it much more difficult to conclusively offer the reason for this discrepancy which is also beyond the scope of this study suggesting a research interest for the future.

However, wide variation of incidence has been attributed to degree of genital tract pathologies and contraceptive practice of the population ${ }^{3}$.

The intra-country variation of incidence was obvious in Nigeria context where three regions showed different incidence ${ }^{11,16,19}$. All were hospital based studies but with potential differences in the degree of genital tract pathology, contraceptive practice, culture, religion and socio-economic strata. The impact of these factors may be explored further suggesting a research interest of the future. Also we observed in the studies that different denominators were used which will further make comparison extremely difficult ${ }^{11}$.

In our study we recorded $0.2 \%$ incidence which was in the middle of world-wide variation of incidence of ectopic pregnancy (EP). The Gambia has wide antenatal care coverage where $94 \%$ of the pregnant mother attends antenatal care at least once and many $(75 \%)$ achieve 4 visits, however, $18 \%{ }^{20}$ of women delivered in health facilities country wide. The low hospital delivery may not affect incidence of ectopic pregnancy as 95\% occur in the fallopian tubes which may not accommodate pregnancy to point of delivery. What was pertinent and not exclusive to the Gambia is cultural and religious reasons that discourage autopsy as many women who presented with abdominal pain in the health facilities may die with EP undiagnosed.

The majority of EP recorded was ruptured (79\%) which suggests late diagnosis.

Poor health seeking behaviour associated with ignorance and poverty may have contributed to late presentation but institutional factors (inadequate manpower, limited availability of consumables, equipment and appropriate test kits) may have also contributed to late diagnosis in this series as these women may have visited 
a health centre before being referred (91\%) (fig 2) to our tertiary hospital with ruptured EP (79\%).

Occupation of the patients had no significant association to ruptured or unruptured EP (p-0.421). Most of the women were housewives $86 \%$ and $14 \%$ of the women were government workers.

Regarding ruptured EP (79\%) our finding was similar to Obed et al ${ }^{21}$ where $5.43 \%$ cases were unruptured EP. Other studies conducted elsewhere recorded more than $70.1 \%$ cases of ruptured $\mathrm{EP}^{22,23,24}$. Ikaki et al ${ }^{25}$ recorded $92.8 \%$ cases of ruptured EP and Ekinne et $\mathrm{al}^{26}$ recorded $96.2 \%$.

About $56 \%$ of the patients were between $26-35$ years and were mainly of low parity and about $82 \%$ were married. This was comparable with the findings reported in Volta- Ghana, Nigeria, and Senegal ${ }^{3,11,19,27}$. The peak reproductive age falls within these age range of 21-35 years especially in the Gambia. A woman who has low parity compared to women who has high parity is more likely than not to have ectopic pregnancy $\mathrm{p}-0.001$. This was consistent with the recent evidence that ectopic pregnancy is increasing in young women of low pari$t^{28,29}$. Low parity may be more strongly associated with EP because of the use of certain contraceptives which was not part of this study. However, Ahamed et al ${ }^{30}$ found associations between the occurrence of ectopic pregnancy and low parity with the use of intrauterine contraceptives.

More than half of the patients $(65.1 \%)$ presented with history of abdominal pain in addition to bleeding per vaginam $(16.2 \%)$ and history of amenorrhea $(13.9 \%)$ (fig 1). This was similar report from other countries like Nigeria, and Ghana ${ }^{11,3}$. No patient presented asymptomatically or with features of shock as seen in Nigeria reports11. However, scholars working in Ireland Chudhary et $\mathrm{al}^{31}$ reported cases of EP that presented with shock. It can then be said that a patient that presents with abdominal pain, bleeding and amenorrhea should be triage immediately and considered to have ectopic pregnancy (EP) until proven otherwise.

The main risk factors the women had was pelvic inflammatory disease $(27.9 \%)$ which was not comparable with Smitre et $a^{32}$ where previous tubal surgery accounted for $40 \%$ of women who presented. Induced abortion 95.9\% was found to be highest risk factor in SouthSouth Nigeria ${ }^{16}$. Other studies conducted in the sub-region recorded high rates of pelvic inflammatory disease as the common risk factor ${ }^{23,33}$ which was comparable with our findings. These differences may be due to variance in the geography, sexual and personal

behaviour of the patients.

The trend of ectopic pregnancy shows in 2016 a peak in February and a sharp drop in March, it peaks again between July and August. In 2017 the peak months were between January and February, a drop was seen with another sharp rise occurring between August and December. In 2018 the peak is seen in February and April.

The trends found in this study over the time period of two years (January 2016 to April 2018)shows that most cases of ectopic pregnancy occurred during the months of August to February, and the least cases were seen between March and July. The peak months for each year were not widely varied as August is the peak month for 2016 and October was the peak month for 2017 with February and April being the peak month for 2018. August to February accounts for most of the wet and cold seasons in the Gambia, so it could be expected that more sexual activity would take place during this period, leading to pregnancy and thereby giving rise to some cases of ectopic pregnancy. The periods with the low cases were attributed to dry seasons of the Gambia.

\section{Conclusion}

Socio-demographic factors most affected by ectopic pregnancy includes age between 26-35 years and low parity $(<4)$. A woman with low parity is more likely to have EP than a woman with high parity. The risk factors associated with ectopic pregnancy were pelvic inflammatory disease and previous history of abortion. Age and parity showed significant association with EP. Occupation had no association with ruptured and unruptured EP. It appears that the periods of high incidence of EP were seasonal more in the cold and rainy season.

\section{Recommendations}

- Ectopic pregnancy is yet a significant contributor to the burden of maternal mortality. The most common risk factor being pelvic inflammatory disease which can be effectively treated if diagnosed early. The fact that it affects the majority of the young population makes it a public health issue.

- More focus should be put on sensitizing the community about ectopic pregnancy, the risk factors, the danger signs and the symptoms it comes with.

- Sensitize women and young girls on ways of preventing sexually transmitted diseases. 
- Health workers should always screen for pelvic infections, sepsis and treat appropriately if discovered.

\section{Limitations of the study}

The fact that patient's files from records were used means that there were issues with correct documentation, missing information and misplaced files.

\author{
Abbreviations \\ EFSTH -Edward Francis Small Teaching Hospital \\ EP - Ectopic Pregnancy \\ PID - Pelvic inflammatory disease \\ REP- Ruptured ectopic pregnancy \\ SDG: sustainable development goals \\ UREP: Unruptured ectopic pregnancy \\ WHO: World Health Organization.
}

\section{Authors' contributions}

MA and TG conceived the study and contributed to the study design, data collection, and data analysis. MA wrote the manuscript. All authors read and approved the final manuscript.

\section{Acknowledgements}

The authors wish to thank Amie Jobarteh and all members of the hospital medical records for help with the patient's folders retrieval and relevant dataset for total number of pregnancies in the period under review.

\section{Competing interests}

The authors declare that they have no competing interests.

\section{Availability of data and materials}

The datasets generated and/or analysed during this study are available from the corresponding author on reasonable request.

\section{Consent to publish}

Not applicable.

\section{Ethics approval and consent to participate}

Ethical clearance to undertake this study was sought from the Research and Publication Committee at the School of Medicine and Allied Health Sciences, University of The Gambia and approval was granted. Patient's folders were careful kept and their identifiable information was neither used nor shared. Consent to participate in the study was waived as this was a retrospective analysis of medical records.

\section{Funding}

The authors did not receive any funding from any source to carry out this study.

\section{References}

1. Togas T. Ectopic pregnancy: epidemiology, risk factors and anatomic site. J Obstet Gynaecol India. $2015 \mathrm{Jul}$; 65(4): 284-285.

2. Tahimina S,Mary D, Preethy S. Clinical analysis of ectopic pregnancy in a tertiary care centre in southern India. JCDR. 2016;10:QC13-QC16.

3. Oppong A.A, Agbemenyan HY, Afeke I, Attachie I, Jamfaru I, Orish V.N(2016). Ectopic pregnancy in a referral hospital in the volta region of Ghana, West Africa. Open Access Library Journal. 2016;3:e2983.

4. Vicken P, Ellen W. Ectopic pregnancy: practice essentials, background, etiology. https://emedicine.medscape.com/article/2041923-overview 2017; retrieved December 2017.

5. Majhi AK, Roy N, Kamakar KS, Barnerjee PK. Ectopic pregnancy- a analysis of 180 cases. J Indian Med Association. 2007;105:308,312. PubMed

6. Igwegbe AO, Eleje GU, Okpala. BC. An Appraisal of the management of ectopic Pregnancy

in a Nigerian Tertiary Hospital. Ann Med and Health Sci Res. 2016;3(2):166-170.

7. Celestial OJ, Justina OA. Ectopic pregnancy experience in a tertiary health facility in South-

South Nigeria . TNHJ. 2016;16(1):1-15. PubMed

8. Ashraf Moini, Reihaneh Hosseini, and Mohammad

RA. Risk factors for ectopic pregnancy: A case- control study. J Res Med Sci. 2014 sep:(19):844-849

9. Horne AW, Critchley HO. Mechanisms of disease: the endocrinology of ectopic pregnancy. Expert Rev Mol Med. 2012 Mar 2; 14:e7. Epub 2012 Mar 2.

10. Kashanian M,Baradaran HR, Mousavi SS, Sheikhansari N, Barapour FJ. Risk factors in ectopic pregnancy and differences between adults and adolescent, is consanguinity important? J Obstet Gynaecol. 2016;36:935-9.

11. Dattito Im, Ol-naffy AU, Aminu BM, Aliyu LD, Kadas SA. Ectopic pregnancy in Bauchi, North- Eastern Nigeria. Trop Jrnal. 2014;31:78-82.

12. Kwawukume E.Y, Ekele B.A; Ectopic pregnancy; In: Comprehensive Gynaecologyin the Tropics, ed. E.Y. Kwawukume. B.A. Ekele, K.A. Danso, E.E .Emuveyan $2^{\text {nd }}$ Edition. Published by G-Pak; printing press Ltd. 2017. Pg 98.

13. Elson CJ, Salim R, Potdar N, Chetty M, Ross JA, Kirk EJ on behalf of the Royal College of Obstetricians and Gynaecologists. Diagnosis and management of ectopic pregnancy. BJOG 2016;:123:e15-e55. 
14. Idoko P, Anyanwu M, Base S. A retrospective analysis of trend of maternal mortality at the Gambian tertiary health centre. BMC Res Notes (2017) 10:493 DOI 10.1186/s13104-017-2817-0

15. Aziz S, Al-wafi B, Swadi HA. Frequency of ectopic pregnancy in a medical centre, kingdom of Saudi Arabia. J Pak Med Assoc. 2011;61(3):221-4.

16. Celestial OJ, Justina OA. Ectopic pregnancy experience in a tertiary health facility in South-South Nigeria. TNHJ. 2016;16(1):1-15.

17. Florin-Andrei Taran, et. al. The Diagnosis and Treatment of Ectopic Pregnancy. Dtsch Aratebl Int. 2015 Oct; 112(41): 693-704. doi: 10.3238/arztebl.2015.0693 18. Debra B. S, Loretta R. C, Irma D, Diane S. L. Ectopic Pregnancy Rates in the Medicaid Population. $A m$ J Obstet Gynecol. 2013 Apr; 208(4): 274.e1-274.e7.

19. Aierede LR, Ekele BA. Ectopic pregnancy in Sokoto, Northern Nigeria. Malawi Medical Journal. 2005;17(1):14 16.

20. Jallow A. Why are there low institutional delivery rates in Gambia? Women's opinion. https://www.duo. uio.no/handle/10852/30143;retrieved 20 ${ }^{\text {th }}$ May 2018.

21. Obed SA. Diagnosis of unruptured ectopic pregnancy is still uncommon in Ghana. Ghana Med J. 2006;40(1):3-7.

22. Udigwe GO, Umeonunihu OS, Mbachu II. Ectopic Pregnancy: A Five Year Review Of Cases At Nnamdi Azikiwe University Teaching Hospital (NAUTH), Nnewi, Nigeria. Niger J Med. 2010, 51(4):160-165.

23. Panti A, Ikechukwu NE, lukman OO, Yakubu A, Egondu SC, Tanko BA. Ectopic pregnancy at Usmanu Danfodiyo University Teaching Hospital Sokoto: a ten year review. Ann Niger Med. 2012;6(2):87-91.

24. Osaikhuwuomwan JA, Aderoba AA, Ande AB. Ec- topic pregnancy in an urban tertiary centre in Southern Nigeria: E merging trends. Afr J Trop Med Biomed Res 2012; 1(3):11-17.

25. Iklaki CU, Emechebe CI, Njoku CO, Ago BU, Ugwu B. Review of ectopic pregnancy as a

cause of Maternal morbidity and mortality in a developing country. IOSR J Dental Med Sci 2015; 14(8): 86-91 26. Ekine AA, Harry CT, Ibrahim IA, Abasi I. Ectopic pregnancy in NDUTH, Okolobiri 5-year case retrospective review. Ind J Med Res Pharm Sci 2014; 1(7):10-19. 27. Cisse CA, Bernis LD, Faye el HO, Diadhiou F. Ectopic Pregnancy in Senegal. Sante. 2002;12(2):271-274. [PubMed] [Google Scholar]

28. Ahmed A,Yasser M,Ibrahim E, Muhammed A,Mohammed A. predictors of ectopic pregnancy in nulliparous women; A case-control study. Middle East Fertility Society Journal. 2016;21(1):27-30.

29. Isabu PA, Eifediyi R.A, Umelo C,Ikehelo I, Affusim C. Trends of ectopic pregnancy in a Nigerian sub-rural teaching hospital. Stand Global J Med Sci. 2014;1(4):8290 .

30. Ahammed R,Yesser M, El-Bahol I, Fawzy M. Predictors of ectopic pregnancy in nulliparous women: A case-control study. Middle East Fertility Society Journal. 2016;21:27-30.

31. Chudhary et al. The management of ectopic pregnancy. Irish Medical Journal. 2008;101(3):22-28.

32. Smitra S, Mahendra G, Vijayalakshmi S,Ravindra S. Clinical study of ectopic pregnancy in a rural setup: A two year survey. National Journal of Med Res. 2014;4(1):37-9.

33. Gharoro EP, Igbafe AA. Ectopic pregnancy revisited in Benin City, Nigeria: analysis of 152 cases. Acta Obstet Gynecol Scand 2002;81(12): 1139-1143. 